\title{
Evaluation of Mechanical Properties of Medium Carbon Steel Quenched in Water and Oil
}

\author{
J. K. Odusote' ${ }^{1}$, T. K. Ajiboye ${ }^{2}$, A. B. Rabiu ${ }^{2}$ \\ ${ }^{1}$ Department of Metallurgy and Material Engineering, University of Ilorin, Ilorin, Nigeria \\ ${ }^{2}$ Department of Mechanical Engineering, University of Ilorin, Ilorin, Nigeria \\ Email: engrtkajiboye@yahoo.com
}

Received March 7, 2012; revised April 10, 2012; accepted April 30, 2012

\begin{abstract}
Samples of medium carbon steel were examined after heating between $900^{\circ} \mathrm{C}-980^{\circ} \mathrm{C}$ and soaked for 45 minutes in a muffle furnace before quenching in palm oil and water separately. The mechanical behavior of the samples was investigated using universal tensile testing machine for tensile test and Vickers pyramid method for hardness testing. The microstructure of the quenched samples was studied using optical microscope. The tensile strength and hardness values of the quenched samples were relatively higher than those of the as-cast samples, suggesting improved mechanical properties. However, samples quenched in palm oil displayed better properties compared with that of water-quenched samples. This behavior was traced to the fact that the carbon particles in palm oil quenched samples were more uniform and evenly distributed, indicating the formation of more pearlite structure, than those quenched in water and the as-received samples.
\end{abstract}

Keywords: Medium Carbon Steel; Muffle Furnace; Quenching Media; Tensile Strength; Hardness Value

\section{Introduction}

Plain carbon steels are widely used for many industrial applications and manufacturing on account of their low cost and easy fabrication [1]. Their major alloying element is carbon, and classified based on their carbon contents. According to Rajan et al. [2], steels with carbon content varying from $0.25 \%$ and $0.65 \%$ are classified as medium carbon, while those with carbon up $0.25 \% \mathrm{C}$, are termed low carbon. High carbon steels usually have carbon content ranges between $0.65 \%-1.5 \%$. Hardness and other mechanical properties of plain carbon steels increase with the rise in concentration of carbon dissolved in austenite prior to quenching during hardening heat treatment $[2,3]$, which may be due to transformation of austenite into martensite [4]. Thus, the mechanical strength of medium carbon steels can be improved by quenching in appropriate medium. However, the major influencing factors in the choice of the quenching medium are the kind of heat treatment, composition of the steel, the sizes and shapes of the parts [5].

Based on the parameter of "quenching severity" $\mathrm{H}$, cooling capacity of water is treated to be unity [6]. The $\mathrm{H}$-parameters of various quenching media, which reflects their capacity for removing heat in the quenching process, are thus compared with that of water. Mineral oils have been found to exhibit best cooling capacity for the majority of alloy steels [7], but they are relatively expensive, toxic and non-biodegradable. Therefore, there has been considerable work in the past on the possibility of replacing mineral oils with aqueous solutions of chemical substances and polymers [7-9]. More recently, the use of local available cooking oils, which are relatively cheap, non-toxic and environmental friendly, as quenching media, has begun to generate attention [10]. In the present study, medium carbon steel samples are heat-treated at different temperature above the austenitic region and quenched in water and palm oil, in order to investigate the effect of different heating and quenching regimes on the mechanical properties of the steel. The changes in mechanical behavior as compared with un-quenched samples are explained in terms of microstructural development within the surface and changes in tensile strength and hardness after quenching treatments.

\section{Materials and Method}

The chemical composition of medium carbon steel samples used for this investigation is given in Table $\mathbf{1}$.

\subsection{Test Specimen Preparation}

As set of specimens were prepared for hardness tests and microstructural analyses. Tensile test specimens were also produced from the as-received medium carbon steel samples of the same composition. The specimens were prepared 
after series of machining operation following the International Test Standard, as shown in Figure 1. Other set of specimens were also prepared for hardness tests and microstructural analysis.

\subsection{Heat Treatment and Quenching}

The prepared tensile test samples and other samples were heated to $900^{\circ} \mathrm{C}, 940^{\circ} \mathrm{C}$ and $980^{\circ} \mathrm{C}$ and soaked for 45 minutes using a muffle furnace. Test samples were quickly taken out of the furnace after each of the heat treatment temperatures, and quenched in water and palm oil separately. Surface morphologies of the quenched samples were examined, and hardness and tensile test were also carried out on each of the samples.

\subsection{Mechanical Test}

\subsubsection{Tensile Testing}

Tensile test were carried out on both the water and palm oil quenched specimens using Instron Universal Tester. Each of the specimens was loaded till fractured, and the fracture load for each sample was recorded as well as the diameter at the point of fracture and the final gauge length. The initial diameter and initial gauge length for each sample was noted before the application of the uniaxial load. The percentage elongation and reduction of each sample was determined, and the ultimate tensile strength and yield strength were obtained from the data generated.

\subsubsection{Hardness Test}

Vickers pyramid method was used for the determination of the hardness of the quenched samples. Each of the test specimens was flatten after the different heating and quenching regimes, and then mounted on the anvil. The specimens were brought in contact with the pyramid indenter and allowed to rest for a dwell time. The hardness of the specimen is indicated by the penetration of the indenter on the test specimen, and displayed by the machine. Average values were recorded after repeating the test for each of the test specimens.

\section{Results and Discussion}

Table 2 shows the mechanical properties of the quenched steel samples compared with the un-quenched samples at different heat treatment temperatures. The effects of the heat treatment temperatures on the tensile strength, Young's modulus of elasticity, percentage elongation and hardness of both the water quenched and oil quenched test samples are shown in Figures 2-5, respectively.

As shown in Figure 2, the tensile strength of both the water quenched and oil quenched samples increases with increase in the heat treatment temperature. The increase in the tensile strength of the quenched samples as compared with that of un-quenched (as-received) sample showed that the heat treatment and quenching operations influenced the strength of the steel samples. However, the tensile strength of the water quenched samples were

Table 1. Chemical composition of the mild steel sample (wt\%).

\begin{tabular}{ccccccccccccc}
\hline Element & $\mathrm{C}$ & $\mathrm{Si}$ & $\mathrm{S}$ & $\mathrm{P}$ & $\mathrm{Mn}$ & $\mathrm{Ni}$ & $\mathrm{Cr}$ & $\mathrm{Mo}$ & $\mathrm{V}$ & $\mathrm{Cu}$ \\
Average content & 0.3302 & 0.1894 & 0.0453 & 0.0527 & 0.7580 & 0.1090 & 0.1170 & 0.1169 & 0.0018 & 0.0033 \\
\hline Element & $\mathrm{W}$ & $\mathrm{As}$ & $\mathrm{Sn}$ & $\mathrm{Co}$ & $\mathrm{Al}$ & $\mathrm{Pb}$ & $\mathrm{Ca}$ & $\mathrm{Zn}$ & $\mathrm{Fe}$ & \\
Average content & 0.0878 & 0.0028 & 0.0204 & 0.0124 & 0.0006 & 0 & 0 & 0.0034 & 98.0413 \\
\hline
\end{tabular}
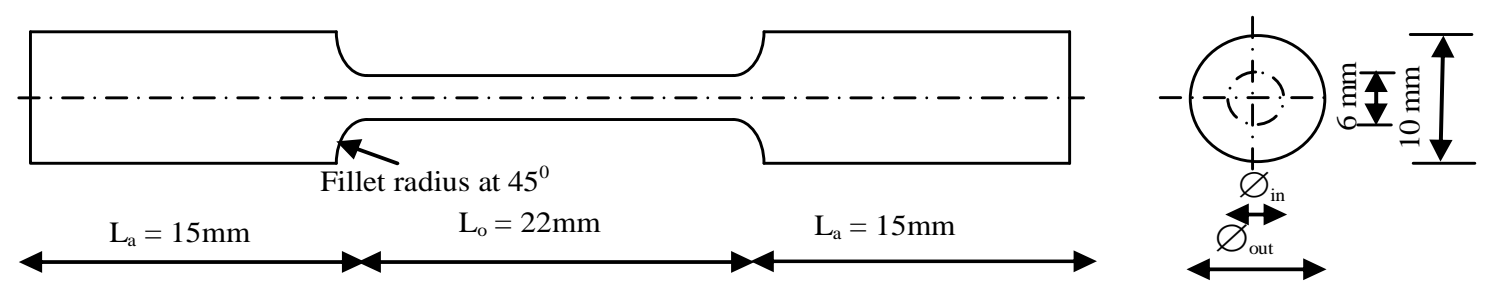

Figure 1. Tensile test specimen from medium carbon steel.

Table 2. Effect of cooling rates on the mechanical properties of medium carbon steel.

\begin{tabular}{|c|c|c|c|c|c|}
\hline Sample quenching medium & Temperature $\left({ }^{\circ} \mathrm{C}\right)$ & $\begin{array}{l}\text { Tensile strength } \\
\left(\mathrm{N} / \mathrm{mm}^{2}\right)\end{array}$ & $\begin{array}{l}\text { Modulus of elasticity } \\
\qquad\left(\mathrm{N} / \mathrm{mm}^{2}\right)\end{array}$ & \% Elongation & Hardness (VHN) \\
\hline As-received & - & 649.4 & 2020.0 & 32 & 286 \\
\hline Water & 900 & 852.2 & 3436.6 & 24.8 & 376 \\
\hline Water & 940 & 905.6 & 2959.5 & 30.6 & 418 \\
\hline Water & 980 & 1063.9 & 3409.9 & 31.2 & 464 \\
\hline Oil & 900 & 834.1 & 2598.4 & 32.1 & 336 \\
\hline Oil & 940 & 889.2 & 2569.9 & 34.6 & 394 \\
\hline Oil & 980 & 996.7 & 2831.5 & 35.2 & 438 \\
\hline
\end{tabular}




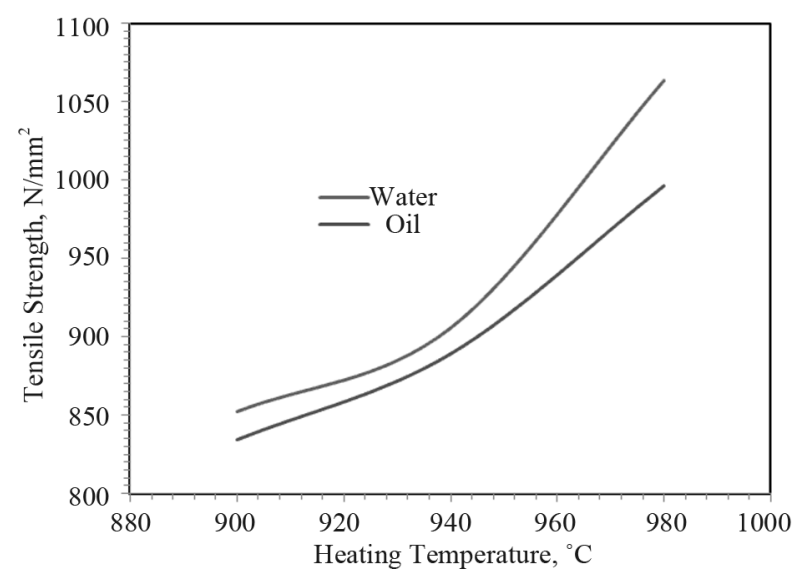

Figure 2. Change in tensile of the medium carbon steel on quenching in water and oil after heating to different.

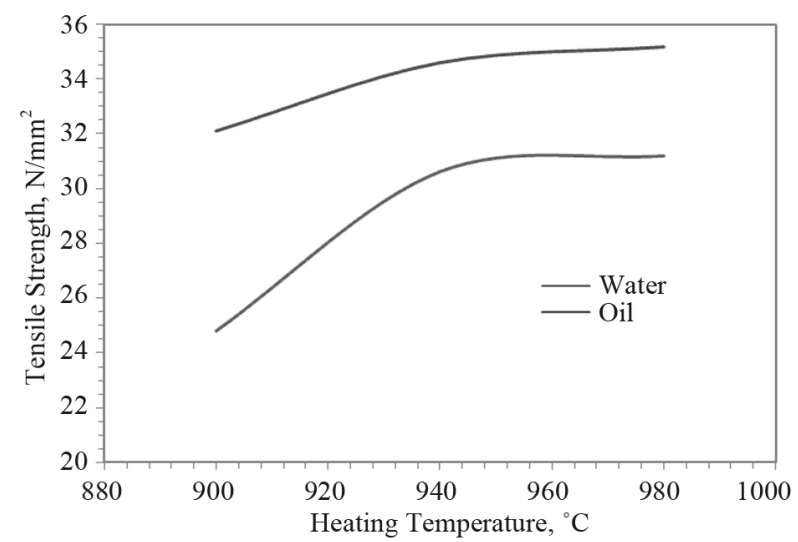

Figure 3. Change in \% elongation of a medium carbon steel on quenching in water and oil after heating to different temperatures; soaking 45 minutes.

higher than those quenched in oil, which may be to due to formation of fine pearlite as a result of fast cooling [11]. Ndliman [10] investigated the mechanical properties of a medium carbon steel heat treated at $850^{\circ} \mathrm{C}$ and quenched in both water and oil. He found that the tensile strength of the heat treated samples were higher than that of the standard AISI C1035 steel sample, with water quenched sample showing higher strength.

Figure 3 shows that the percentage elongation of the steel samples increased with increasing heating temperature for both quenching media. However, the elongation tends to improve for oil quenching compared with water quenching, as faster cooling rate has been reported to have a negative effect on elongation [11]. Transformation temperature is lowered by increased cooling rate, and finer peralite grains are formed at lower temperatures [12]. Martensitic structure, which has a detrimental effect on toughness, is also produced during continuous water quenching [13].

The Young's Modulus values were calculated from the tensile strength and strain values, and the graph is pre-

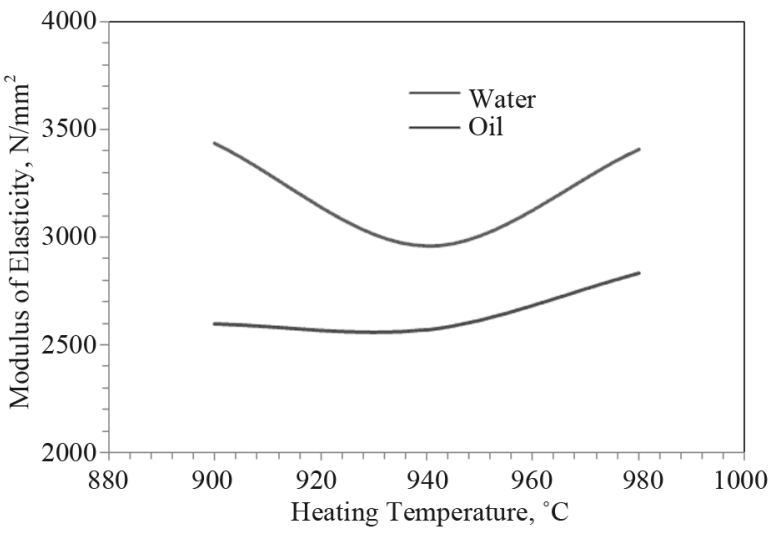

Figure 4. Varition of young modulus of a medium carbon steel on quenching in water and oil after heating to different temperatures; soaking 45 minutes.

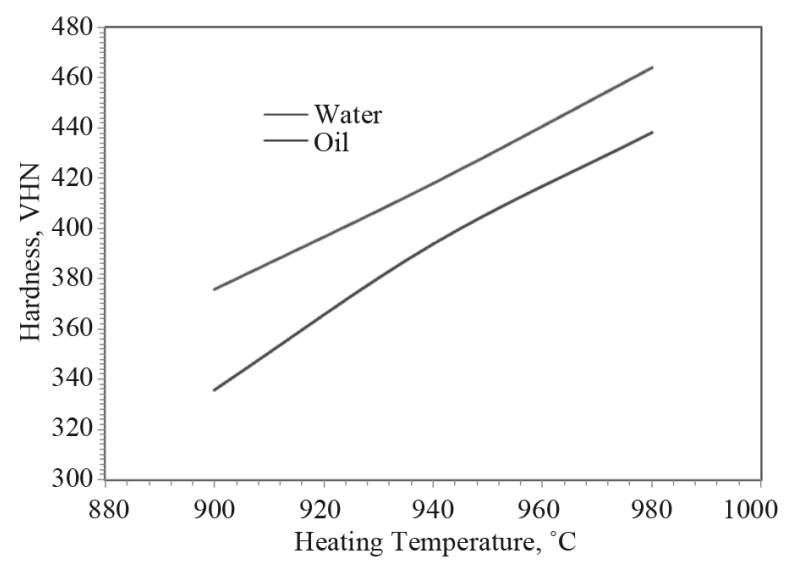

Figure 5. Change in hardness values of a medium carbon steel on quenching in water and oil after heating to different temperatures; soaking 45 minutes.

sented in Figure 4. From the Figure, it is revealed that the value decreased with increasing temperature from $900^{\circ} \mathrm{C}$ to $940^{\circ} \mathrm{C}$ for both the water quenched and oil quenched samples. Above $940^{\circ} \mathrm{C}$, the value further decreased for the water quenched sample, while it slightly increased for the oil cooled sample, indicating possible improvement.

The hardness measurement, Figure 5, showed that water quenched samples had higher Vickers hardness compared to oil quenched samples. This may be due to faster cooling rate of water, resulting in highest free carbon in martensite [11]. Furthermore, presence of fine dispersion of small particles in the pro-eutectoid ferrite and pearlitic ferrite, which will hinder the dislocation movement, may have also contributed to higher hardness value of the water-quenched sample.

\section{Conclusions}

1) It has been established that palm oil can also be used as a quenching medium for medium carbon steel, 
since mechanical strength of some of the samples quenched with palm oil improved when compared with those of the as-received sample.

2) Quenching in water resulted in higher tensile strength and hardness possibly due to formation of martensitic structure after quenching.

3) Palm oil cooling improves the ductility of the steel because of its lower cooling rate compared with water. Thus, palm oil will be a viable quenching medium, where improve elongation of the sample is critical.

\section{REFERENCES}

[1] W. F. Smith and J. Hashemi, "Foundation of Materials Science and Engineering," 4th Edition, McGraw-Hill, New York, 2006.

[2] T. V. Rajan, C. P. Sharma and A. Sharma, "Heat Treatment-Principles and Techniques," Prentice-Hall of India Private Limited, New Delhi, 1988, p. 451.

[3] K. E. Thelning, "Steel and Its Heat Treatment," 2nd Edition, Butterworth, London, 1984, p. 145.

[4] C. Feng and T. I. Khan, "The Effect of Quenching Medium on the Wear Resistance of a Ti-6Al-4V Alloy," Journal of Materials Science, Vol. 43, No. 2, 2008, pp. 788-792. doi:10.1007/s10853-007-2298-y

[5] J. Rassizadehghani, Sh. Raygan and M. Askari, "Comparison of the Quenching Capacities of Hot Salt and Oil Baths,” Metal Science and Heat Treatment, Vol. 48, No. 5-6, 2006, pp. 8-11. doi:10.1007/s11041-006-0069-z
[6] G. Krauss, "Steels: Heat Treatment and Processing Principles,” ASM International, Russell Township, 1990, pp. 125-345.

[7] S. A. Grishin and Yu. N. Churyukin, "Evaluation of the Cooling Capacity of Quenching Media Based on Water," Metal Science and Heat Treatment, Vol. 30, No. 5, 1986, pp. 86-88.

[8] A. I. Kulikov, “A New Quenching Medium for Metals and Alloys," Metal Science and Heat Treatment, Vol. 39, No. 11-12, 1997, pp. 528-530. doi:10.1007/BF02471373

[9] A. V. Tolstousov and O. A. Bannykh, "New Quenching Media Based on Water-Soluble Polymers,” Metal Science and Heat Treatment, Vol. 23, No. 2, 1981, pp. 104-106. doi:10.1007/BF01226357

[10] M. B. Ndaliman, “An Assessment of Mechanical Properties of Medium Carbon Steel under Different Quenching Media,” AU Journal of Technology, Vol. 10, No. 2, 2006, pp. 100-104.

[11] S. Gündüz and A. Çapar, "Influence of Forging and Cooling Rate on Microstructure and Properties on Medium Carbon Microalloy Forging Steel," Journal of Materials Science, Vol. 41, No. 2, 2006, pp. 561-564. doi:10.1007/s10853-005-4239-y

[12] D. R. Askeland, "The Science and Engineering of Materials,” Chapman and Hall, London, 1996, p. 239.

[13] I. Madariage, I. Gutierrez, A. C. Garcia-de and C. Capdevilla, "Acicular Ferrite Formation in a Medium Carbon Steel with a Two Stage Continuous Cooling," Scripta Materialia, Vol. 41, No. 3, 1999, pp. 229-235. doi:10.1016/S1359-6462(99)00149-9 